\title{
Full Scan MS in Comprehensive Qualitative and Quantitative Residue Analysis in Food and Feed Matrices: How Much Resolving Power is Required?
}

\author{
Markus Kellmann, ${ }^{\mathrm{a}}$ Helmut Muenster, ${ }^{\mathrm{a}}$ Paul Zomer, ${ }^{\mathrm{b}}$ and Hans $\mathrm{Mol}^{\mathrm{b}}$ \\ a Thermo Fisher Scientific, Bremen, Germany \\ ${ }^{\mathrm{b}}$ RIKILT Institute of Food Safety, Wageningen, The Netherlands
}

In LC full scan based MS screening methods correct mass assignment is essential. Parameters affecting the accuracy of mass assignment, i.e., analyte concentration, complexity of the matrix, and resolving power, were studied using typical examples from the field of residue and contaminant analysis in food and feed. The evaluation was carried out by analyzing samples of honey and animal feed, spiked with 151 pesticides, veterinary drugs, mycotoxins, and plant toxins at levels ranging from 10 to $250 \mathrm{ng} / \mathrm{g}$. Analyses were performed using a single stage Orbitrap with resolving power settings varying from 10,000 to 100,000 (FWHM). For consistent and reliable mass assignment ( $<2 \mathrm{ppm}$ ) of analytes at low levels in complex matrices, a high resolving power $(\geq 50,000)$ was found to be required. At lower resolving power settings, the error in the assignment of mass increased due to the coelution of analytes with interferences at the same nominal mass. This negatively affected selectivity and quantitative performance due to the inability to use the required narrow mass-extraction windows. In the case of the less complex honey matrix, a resolving power of 25,000 was generally sufficient to obtain a mass assignment error close to the typical instrument mass accuracy ( $\leq 2 \mathrm{ppm}$ ) down to low concentration levels of $10 \mathrm{ng} / \mathrm{g}$. (J Am Soc Mass Spectrom 2009, 20, 1464-1476) @ 2009 Published by Elsevier Inc. on behalf of American Society for Mass Spectrometry

$\mathrm{T}$ The potential presence of residues and contaminants is an important issue in the field of food and animal feed safety. Consequently, legislation has been established at both the national and international level to protect consumers from exposure to food toxicants (e.g., [1-5]). This results in the need for monitoring and control of such compounds in the food chain. With new toxicants being identified and increasing consumer awareness, the number of compounds and the demand for analysis continue to grow.

The variety of potential sample types is enormous. It varies from raw materials of plant and animal origin to finished processed food. Target compounds are mainly small molecules with molecular weights in the range of 100-1000 Da (majority 200-400 Da). Typical examples are residues of pesticides and veterinary drugs, natural toxins, environmental contaminants, processing and packaging contaminants, and spoilage markers. The total number of compounds of interest is therefore very high (thousands).

In analytical chemistry, there is a clear tendency to combine and expand existing analytical methods within the different contaminant classes and beyond [6]. This is

Address reprint requests to Dr. M. Kellmann, Thermo Fisher Scientific, Hanna-Kunath Str. 11, 28199 Bremen, Germany. E-mail: markus.kellmann@ thermofisher.com more efficient (less methods $=$ less costs) and more information is obtained during analysis.

Currently, multianalyte methods are typically carried out using high-performance liquid chromatography (HPLC) coupled to triple quadrupole mass spectrometers (QqQ-MS). Although the methods are highly selective and yield precise, quantitative results, this approach has drawbacks and limitations, which are inherent to the targeted acquisition involved in the MS measurement:

- Optimization of acquisition parameters is required for every single compound, resulting in extensive method set-up (time-consuming)

- The number of compounds is limited in one instrumental method

- Only analytes included in the MS-acquisition method will be detected

- Definition of acquisition-time windows is required for each (group of) analyte(s). In practice, the correct settings of these time windows needs constant attention to assure detection of the analyte

- Retrospective data analysis cannot be carried out

This in part, explains why for chemical screening methods there has been an increased interest in full scan mass spectrometric analysis (i.e., untargeted measure- 
ment) as an alternative to the tandem mass spectrometers [7-12].

The sample extracts to be analyzed, in the case of wide-scope screening, are highly complex due to the use of simple generic sample preparation procedures (often just extraction/dilution). The lack of selectivity from this sample preparation step has to be compensated for by selectivity in the instrumental analysis. With legal residue limits in the order of $\mathrm{ng} / \mathrm{g}$, this means that the full scan MS detection has to fulfill the following requirements:

- High selectivity for every single compound in the mixture

- High sensitivity

- Confirmation of compound identity

- Accurate quantification of analytes found

It has been shown that these requirements can be met using mass spectrometers with high mass resolving power and high mass accuracy. Food safety applications described in literature - using full scan analysis mostly describe the highly effective use of TOF-MS for the detection and identification of pesticides in vegetables/fruits [8-10] and water [8], veterinary drugs in milk [12] and meat [11], and perfluorinated compounds in biota [7]. From these results it is clear, that high accuracy of mass assignment, irrespective of the matrix, the analyte and its concentration, is mandatory.

The accuracy of mass assignment in a measurement can differ from the instrumental mass accuracy, which usually is specified by the instrument vendors under certain conditions. One main influence on the assignment of masses is the ability of a mass spectrometer to resolve two peaks on the $m / z$ scale, which are close to each other. When peaks are not (fully) resolved, the resulting measured mass profile will be the sum of the two individual mass profiles and the top of the combined profile will lie somewhere in between the exact masses of the two individual peaks, as has also been pointed out elsewhere [13]. As a consequence, the mass assignment, which is based on a centroiding algorithm of the detected profile, will result in an incorrect mass for the analyte (for illustration of this effect see Supplemental Figure 4, which can be found in the electronic version of this article.) Note that instrument mass accuracy itself is not affected by this phenomenon. A different $\mathrm{m} / \mathrm{z}$ region in the same mass spectrum can be free of interferences and show correct mass assignment of analytes.

Moving towards higher complexity of the samples (high number of matrix peaks at high levels relative to the analytes) the resolution power of a mass spectrometer can become a key parameter for the correct assignment of analyte masses. In the current work, emphasis was placed on the evaluation of this effect in target compound screening in real samples and its impact on quantitation.
For the evaluation, a recently introduced single stage Orbitrap mass spectrometer was used. Since its first description in 2000 [14] and its commercial introduction in 2005, Orbitrap technology has demonstrated its high resolving power and precise mass measurement capabilities [15-18]. Until recently, this technology was only incorporated in hybrid-MS systems and typically used in the field of proteomics [19], and metabolomics [20]. With the introduction of a single stage mass spectrometer, Orbitrap technology has become an attractive option for full scan screening in the field of food safety. Since the mass resolving power can be set by the user, the effect of this parameter on the analytical performance could be conveniently studied using one and the same instrument.

For the evaluation, a set of 151 pesticides, veterinary drugs, mycotoxins, and plant toxins in generic extracts of honey and animal feed (10-250 ng/g) was analyzed using resolving power settings between 10,000 and 100,000 .

\section{Experimental}

\section{Chemicals and Reagents}

Reference standards. Analytical standards of pesticides, mycotoxins, plant toxins, and veterinary drugs were purchased as pure materials or as custom-made mixed solutions. Details of suppliers are given elsewhere [6].

Stock solutions at a concentration of 100-2000 $\mu \mathrm{g} / \mathrm{mL}$ were prepared from the pure compound standards. For pesticides, veterinary drugs, and plant toxins, methanol was used as solvent. Mycotoxins and ergot alkaloids were dissolved in acetonitrile. From the stock solutions and the purchased custom-made mix solutions, spiking solutions were prepared in methanol. Two mix-spike solutions were prepared, one containing all pesticides and natural toxins (all at $1 \mu \mathrm{g} / \mathrm{mL}$ ) and another one containing all veterinary drugs (at $0.1-5$ $\mu \mathrm{g} / \mathrm{mL}$, concentrations for individual compounds are included in Table 1). The spike solutions were stored in a freezer $\left(<-18^{\circ} \mathrm{C}\right)$.

Chemicals. Acetonitrile and methanol (all HPLC grade or better) and HPLC grade water were purchased from Fisher Scientific (Schwerte, Germany). Formic acid and ammonium formate were obtained from Sigma-Aldrich (Schnelldorf, Germany).

Sample preparation. Two samples were selected for this work, one of intermediate complexity (honey) and one highly complex feed matrix. Honey was obtained from a local bee-keeper. The feed matrix was a commercially available compound feed sold as horse feed. Compound feeds are feedstuffs that are blended from various raw materials and additives (more details can be found in [6]).

Sample preparation was carried out according to a recently described generic procedure that allows effi- 
Table 1. List of compounds used for evaluation (an overview of the extracted ion chromatograms is given in Suppl. Fig 0.1)

\begin{tabular}{|c|c|c|c|c|c|c|c|}
\hline Index & Type & Compound name & Elemental composition & Exact mass* & & $\mathrm{RT}(\min )$ & Stock $(\mu \mathrm{g} / \mathrm{mL})$ \\
\hline 1 & $\mathrm{P} / \mathrm{PT}$ & Nicotine & $\mathrm{C} 10 \mathrm{H} 14 \mathrm{~N} 2$ & 163.12298 & & 1.18 & 1 \\
\hline 2 & $\mathrm{P}$ & Propamocarb & $\mathrm{C} 9 \mathrm{H} 2 \mathrm{~N} 2 \mathrm{O} 2$ & 189.15978 & $* * * *$ & 3.37 & 1 \\
\hline 3 & VD & Sulfachloropyridazine & $\mathrm{C} 10 \mathrm{H} 10 \mathrm{~N} 4 \mathrm{O} 2 \mathrm{~S}$ & 285.02078 & & 3.54 & 5 \\
\hline 4 & PT & Scopolamine & $\mathrm{C} 17 \mathrm{H} 21 \mathrm{NO} 4$ & 304.1544 & & 3.55 & 1 \\
\hline 5 & $\mathrm{P}$ & Asulam & $\mathrm{C} 8 \mathrm{H} 10 \mathrm{~N} 2 \mathrm{O} 4 \mathrm{~S}$ & 231.04338 & & 3.55 & 1 \\
\hline 6 & VD & Levamisole & $\mathrm{C} 11 \mathrm{H} 12 \mathrm{~N} 2 \mathrm{~S}$ & 205.07938 & & 3.55 & 0.2 \\
\hline 7 & VD & Sulfathiazole & $\mathrm{C} 9 \mathrm{H} 9 \mathrm{~N} 3 \mathrm{O} 2 \mathrm{~S} 2$ & 256.02088 & & 3.58 & 5 \\
\hline 8 & $\mathrm{VD}(\mathrm{m})$ & Albendazole Amino Sulfone & $\mathrm{C} 10 \mathrm{H} 13 \mathrm{~N} 3 \mathrm{O} 2 \mathrm{~S}$ & 240.08008 & & 3.61 & 5 \\
\hline 9 & PT & Retrorsine & C18H25NO6 & 352.1755 & & 3.64 & 1 \\
\hline 10 & VD & Lincomycin & $\mathrm{C} 18 \mathrm{H} 34 \mathrm{~N} 2 \mathrm{O} 6 \mathrm{~S}$ & 407.22108 & & 3.65 & 5 \\
\hline 11 & VD & Trimethoprim & $\mathrm{C} 14 \mathrm{H} 18 \mathrm{~N} 4 \mathrm{O} 3$ & 291.14517 & & 3.67 & 2.5 \\
\hline 12 & VD & Sulfapyridine & $\mathrm{C} 11 \mathrm{H} 11 \mathrm{~N} 3 \mathrm{O} 2 \mathrm{~S}$ & 250.06448 & & 3.67 & 5 \\
\hline 13 & PT & Retrorsine-N-oxide & $\mathrm{C} 18 \mathrm{H} 25 \mathrm{NO} 7$ & 368.1704 & & 3.67 & 1 \\
\hline 14 & VD & Isopyrin & C14H19N3O & 246.16009 & & 3.69 & 5 \\
\hline 15 & VD & Tulatromycine & C41H79N3O12 & 403.7905 & ** & 3.69 & 5 \\
\hline 16 & VD & Marbofloxacin & C17H19FN4O4 & 363.14628 & & 3.71 & 5 \\
\hline 17 & $P$ & Oxamyl & C7H13N3O3S & 220.07508 & & 3.72 & 1 \\
\hline 18 & PT & Seneciphylline & $\mathrm{C} 18 \mathrm{H} 23 \mathrm{NO} 5$ & 334.1649 & & 3.72 & 1 \\
\hline 19 & $\mathrm{VD}(\mathrm{m})$ & 5-Hydroxy thiabendazole & C10H7N3OS & 218.03828 & & 3.74 & 5 \\
\hline 20 & VD & Sulfamerazine & $\mathrm{C} 11 \mathrm{H} 12 \mathrm{~N} 4 \mathrm{O} 2 \mathrm{~S}$ & 265.07538 & & 3.77 & 5 \\
\hline 21 & PT & Heliotrine & C16H27NO5 & 314.1962 & & 3.77 & 1 \\
\hline 22 & PT & Seneciphylline-N-oxide & $\mathrm{C} 18 \mathrm{H} 23 \mathrm{NO} 6$ & 350.1598 & & 3.78 & 1 \\
\hline 23 & PT & Atropine & $\mathrm{C} 17 \mathrm{H} 23 \mathrm{NO} 3$ & 290.1751 & & 3.79 & 1 \\
\hline 24 & VD & Sulfamoxole & $\mathrm{C} 11 \mathrm{H} 13 \mathrm{~N} 3 \mathrm{O} 3 \mathrm{~S}$ & 268.07508 & & 3.81 & 5 \\
\hline 25 & VD & Norfloxacin & $\mathrm{C} 16 \mathrm{H} 18 \mathrm{FN} 3 \mathrm{O} 3$ & 320.14048 & & 3.84 & 2.5 \\
\hline 26 & $\mathrm{P}$ & Carbendazim & $\mathrm{C9H} 9 \mathrm{~N} 3 \mathrm{O} 2$ & 192.07678 & $* * * *$ & 3.85 & 1 \\
\hline 27 & $\mathrm{P}$ & Oxydemeton-methyl & $\mathrm{C} 6 \mathrm{H} 15 \mathrm{O} 4 \mathrm{PS} 2$ & 247.02218 & & 3.85 & 1 \\
\hline 28 & VD & Dapsone & $\mathrm{C} 12 \mathrm{H} 12 \mathrm{~N} 2 \mathrm{O} 2 \mathrm{~S}$ & 249.06918 & & 3.85 & 0.5 \\
\hline 29 & VD & Danofloxacin & C19H2OFN3O3 & 358.15618 & & 3.86 & 3 \\
\hline 30 & VD & Sulfamethizole & $\mathrm{C} 9 \mathrm{H} 10 \mathrm{~N} 4 \mathrm{O} 2 \mathrm{~S} 2$ & 271.03178 & & 3.86 & 5 \\
\hline 31 & VD & Ciprofloxacin & C17H18FN3O3 & 332.14048 & & 3.86 & 0.5 \\
\hline 32 & VD & Enrofloxacin & $\mathrm{C} 19 \mathrm{H} 22 \mathrm{FN} 3 \mathrm{O} 3$ & 360.17178 & & 3.89 & 5 \\
\hline 33 & PT & Senecionine & C18H25NO5 & 336.1806 & & 3.89 & 1 \\
\hline 34 & VD & Azaperol & C19H24FN3O & 330.1976 & & 3.91 & 0.1 \\
\hline 35 & VD & Sulfamethoxypyridazine & $\mathrm{C} 11 \mathrm{H} 12 \mathrm{~N} 4 \mathrm{O} 3 \mathrm{~S}$ & 281.07028 & & 3.95 & 5 \\
\hline 36 & VD & Sulfadimethoxine & $\mathrm{C} 12 \mathrm{H} 14 \mathrm{~N} 4 \mathrm{O} 2 \mathrm{~S}$ & 311.08088 & & 3.95 & 5 \\
\hline 37 & VD & Sulfamethazine & $\mathrm{C} 12 \mathrm{H} 14 \mathrm{~N} 4 \mathrm{O} 2 \mathrm{~S}$ & 311.08088 & & 3.95 & 5 \\
\hline 38 & VD & Tolmetin & $\mathrm{C} 15 \mathrm{H} 15 \mathrm{NO} 3$ & 258.11248 & & 3.95 & 5 \\
\hline 39 & $P$ & Thiamethoxam & C8H10CIN5O3S & 292.02658 & & 3.95 & 1 \\
\hline 40 & PT & Senecionine- $\mathrm{N}$-oxide & $\mathrm{C} 18 \mathrm{H} 25 \mathrm{NO} 6$ & 352.1755 & & 3.98 & 1 \\
\hline 41 & VD & Sulfamethoxazole & $\mathrm{C} 10 \mathrm{H} 11 \mathrm{~N} 3 \mathrm{O} 3 \mathrm{~S}$ & 254.05938 & & 4.06 & 5 \\
\hline 42 & VD & Spiramycin & $\mathrm{C} 43 \mathrm{H} 74 \mathrm{~N} 2 \mathrm{O} 14$ & 422.26428 & $* *$ & 4.06 & 5 \\
\hline 43 & VD & Sulfisoxazole & $\mathrm{C} 11 \mathrm{H} 13 \mathrm{~N} 3 \mathrm{O} 3 \mathrm{~S}$ & 268.07504 & & 4.12 & 5 \\
\hline 44 & PT & Senkikkine & C19H27NO6 & 366.1911 & & 4.12 & 1 \\
\hline 45 & VD & Sulfamonomethoxine & $\mathrm{C} 11 \mathrm{H} 12 \mathrm{~N} 4 \mathrm{O} 3 \mathrm{~S}$ & 281.07028 & & 4.16 & 5 \\
\hline 46 & P/VD & Thiabendazole & C10H7N3S & 202.04338 & & 4.18 & 5 \\
\hline 47 & VD & Sulfadiazine & $\mathrm{C} 12 \mathrm{H} 14 \mathrm{~N} 4 \mathrm{O} 4 \mathrm{~S}$ & 251.05968 & & 4.19 & 5 \\
\hline 48 & PT & Acetyl-Seneciphylline & $\mathrm{C} 2 \mathrm{OH} 25 \mathrm{NO} 6$ & 376.1755 & & 4.36 & 1 \\
\hline 49 & VD & Ibuprofen & $\mathrm{C} 13 \mathrm{H} 18 \mathrm{O} 2$ & 207.13796 & & 4.39 & 1 \\
\hline 50 & $P$ & Dimethoate & C5H12NO3PS2 & 230.00688 & $* * * *$ & 4.46 & 1 \\
\hline 51 & $\mathrm{VD}(\mathrm{m})$ & Amino flubendazole & C14H10FN3O & 256.08808 & & 4.52 & 0.2 \\
\hline 52 & $P$ & Metamitron & $\mathrm{C} 10 \mathrm{H} 10 \mathrm{~N} 4 \mathrm{O}$ & 203.09278 & & 4.54 & 1 \\
\hline 53 & VD & Sulfadoxine & $\mathrm{C} 12 \mathrm{H} 14 \mathrm{~N} 4 \mathrm{O} 4 \mathrm{~S}$ & 311.08088 & & 4.6 & 5 \\
\hline 54 & VD & Tilmicosin & $\mathrm{C} 46 \mathrm{H} 80 \mathrm{~N} 2 \mathrm{O} 13$ & 435.2903 & $* *$ & 4.62 & 5 \\
\hline 55 & $\mathrm{VD}(\mathrm{m})$ & Albendazole Sulfoxide & $\mathrm{C} 12 \mathrm{H} 15 \mathrm{~N} 3 \mathrm{O} 3 \mathrm{~S}$ & 282.09068 & & 4.67 & 5 \\
\hline 56 & VD & Pirlimycine & $\mathrm{C} 17 \mathrm{H} 31 \mathrm{CIN} 2 \mathrm{O} 5 \mathrm{~S}$ & 411.1715 & & 4.69 & 5 \\
\hline 57 & $\mathrm{VD}(\mathrm{m})$ & Albendazole Sulfon & $\mathrm{C} 12 \mathrm{H} 15 \mathrm{~N} 3 \mathrm{O} 4 \mathrm{~S}$ & 298.08558 & & 4.73 & 5 \\
\hline 58 & VD & Sulfaquinoxaline & $\mathrm{C} 14 \mathrm{H} 12 \mathrm{~N} 4 \mathrm{O} 2 \mathrm{~S}$ & 301.07538 & & 4.74 & 5 \\
\hline 59 & $\mathrm{MT}$ & Aflatoxine G2 & $\mathrm{C} 17 \mathrm{H} 14 \mathrm{O} 7$ & 331.0813 & & 4.74 & 1 \\
\hline 60 & VD & Tenoxicam & $\mathrm{C} 13 \mathrm{H} 11 \mathrm{~N} 3 \mathrm{O} 4 \mathrm{~S} 2$ & 338.02637 & & 4.76 & 5 \\
\hline 61 & $P$ & Thiacloprid & $\mathrm{C} 10 \mathrm{H} 9 \mathrm{CIN} 4 \mathrm{~S}$ & 253.03088 & & 4.77 & 1 \\
\hline 62 & VD & Ipronidazol & $\mathrm{C} 7 \mathrm{H} 11 \mathrm{~N} 3 \mathrm{O} 2$ & 170.09238 & $* * * *$ & 4.87 & 0.5 \\
\hline 63 & $\mathrm{MT}$ & Ergosine & С30H37N5O5 & 548.2868 & $* * * *$ & 4.89 & 1 \\
\hline
\end{tabular}


Table 1. Continued

\begin{tabular}{|c|c|c|c|c|c|c|c|}
\hline Index & Type & Compound name & Elemental composition & Exact mass* & & $\mathrm{RT}(\min )$ & Stock $(\mu \mathrm{g} / \mathrm{mL})$ \\
\hline 64 & MT & Aflatoxine G1 & $\mathrm{C} 17 \mathrm{H} 12 \mathrm{O} 7$ & 329.0656 & & 4.92 & 1 \\
\hline 65 & MT & Ergotamine & C33H35O5N5 & 582.2711 & & 5 & 1 \\
\hline 66 & $P$ & Metoxuron & $\mathrm{C} 10 \mathrm{H} 13 \mathrm{CIN} 2 \mathrm{O} 2$ & 229.07388 & & 5.06 & 1 \\
\hline 67 & VD & Haloperidol & $\mathrm{C} 21 \mathrm{H} 23 \mathrm{CIFNO} 2$ & 376.1474 & $* * * *$ & 5.1 & 0.1 \\
\hline 68 & VD & Oxfendazole & $\mathrm{C} 15 \mathrm{H} 13 \mathrm{~N} 3 \mathrm{O} 3 \mathrm{~S}$ & 316.07503 & & 5.19 & 1 \\
\hline 69 & MT & Aflatoxine B2 & $\mathrm{C} 17 \mathrm{H} 14 \mathrm{O} 6$ & 315.0863 & & 5.2 & 1 \\
\hline 70 & $P$ & Carbeetamide & $\mathrm{C} 12 \mathrm{H} 16 \mathrm{~N} 2 \mathrm{O} 3$ & 237.12338 & & 5.22 & 1 \\
\hline 71 & $P$ & Pirimicarb & $\mathrm{C} 11 \mathrm{H} 18 \mathrm{~N} 4 \mathrm{O} 2$ & 239.15028 & & 5.23 & 1 \\
\hline 72 & VD & Oxibendazole & $\mathrm{C} 12 \mathrm{H} 15 \mathrm{~N} 3 \mathrm{O} 3$ & 250.27678 & & 5.26 & 0.2 \\
\hline 73 & $\mathrm{P}$ & Triasulfuron & C14H16CIN5O5S & 402.06338 & & 5.26 & 1 \\
\hline 74 & VD & Piroxycam & $\mathrm{C} 15 \mathrm{H} 13 \mathrm{~N} 3 \mathrm{O} 4 \mathrm{~S}$ & 332.06998 & & 5.27 & 5 \\
\hline 75 & $\mathrm{P}$ & Cyanazine & C9H13CIN6 & 241.09628 & & 5.29 & 1 \\
\hline 76 & $\mathrm{P}$ & Thiophanate-methyl & $\mathrm{C} 12 \mathrm{H} 14 \mathrm{~N} 4 \mathrm{O} 4 \mathrm{~S} 2$ & 343.05288 & & 5.31 & 1 \\
\hline 77 & MT & Diacetyoxyscirpenol & $\mathrm{C} 19 \mathrm{H} 26 \mathrm{O} 7$ & 384.2016787 & $* * *$ & 5.37 & 1 \\
\hline 78 & $P$ & Imazamethabenz-methyl & $\mathrm{C} 16 \mathrm{H} 20 \mathrm{~N} 2 \mathrm{O} 3$ & 289.15468 & & 5.4 & 1 \\
\hline 79 & MT & Aflatoxin B1 & $\mathrm{C} 17 \mathrm{H} 12 \mathrm{O} 6$ & 313.0707 & $* * * *$ & 5.41 & 1 \\
\hline 80 & VD & Acetopromazine & $\mathrm{C} 19 \mathrm{H} 22 \mathrm{~N} 2 \mathrm{OS}$ & 327.1526 & & 5.41 & 0.1 \\
\hline 81 & VD & Tiamulin & $\mathrm{C} 28 \mathrm{H} 47 \mathrm{NO} 4 \mathrm{~S}$ & 494.3299 & & 5.45 & 5 \\
\hline 82 & MT & Ergocryptine & $\mathrm{C} 32 \mathrm{H} 41 \mathrm{O} 5 \mathrm{~N} 5$ & 576.3181 & & 5.48 & 1 \\
\hline 83 & $P$ & Propoxur & $\mathrm{C} 11 \mathrm{H} 15 \mathrm{NO} 3$ & 210.11248 & & 5.54 & 1 \\
\hline 84 & MT & Ergocristine & C35H39O5N5 & 610.3024 & & 5.55 & 1 \\
\hline 85 & $\mathrm{P}$ & Carbofuran & $\mathrm{C} 12 \mathrm{H} 15 \mathrm{NO} 3$ & 222.11248 & $* * * *$ & 5.6 & 1 \\
\hline 86 & VD & Tylosin & $\mathrm{C} 46 \mathrm{H} 77 \mathrm{NO} 17$ & 916.52648 & $* * * *$ & 5.6 & 5 \\
\hline 88 & $\mathrm{P}$ & Simazine & C7H12CIN5 & 202.08538 & & 5.84 & 1 \\
\hline 89 & VD & Propyphenazone & $\mathrm{C} 14 \mathrm{H} 18 \mathrm{~N} 2 \mathrm{O}$ & 231.14918 & & 6.01 & 2 \\
\hline 90 & VD & Propionylpromazine & $\mathrm{C} 2 \mathrm{OH} 24 \mathrm{~N} 2 \mathrm{OS}$ & 341.16818 & & 6.06 & 0.1 \\
\hline 91 & $\mathrm{P}$ & Ethiofencarb & $\mathrm{C} 11 \mathrm{H} 15 \mathrm{NO} 2 \mathrm{~S}$ & 226.08968 & & 6.06 & 1 \\
\hline 92 & VD & Flumequine & $\mathrm{C} 14 \mathrm{H} 12 \mathrm{FNO} 3$ & 262.08738 & & 6.21 & 5 \\
\hline 93 & VD & Indoprofen & $\mathrm{C} 17 \mathrm{H} 15 \mathrm{NO} 3$ & 282.1125 & & 6.29 & 2 \\
\hline 94 & VD & Chlorpromazine & C17H19CIN2S & 319.10298 & & 6.3 & 0.2 \\
\hline 95 & $\mathrm{P}$ & Chlorortoluron & $\mathrm{C} 10 \mathrm{H} 13 \mathrm{CIN} 2 \mathrm{O}$ & 213.07888 & & 6.34 & 1 \\
\hline 96 & $P$ & Fenpropimorph & $\mathrm{C} 2 \mathrm{OH} 33 \mathrm{NO}$ & 304.26348 & & 6.4 & 1 \\
\hline 97 & VD & Josamycin & C42H69NO15 & 828.47398 & & 6.4 & 1 \\
\hline 98 & $\mathrm{P}$ & Metalaxyl & C15H21NO4 & 280.15438 & & 6.47 & 1 \\
\hline 99 & $P$ & Isoproturon & $\mathrm{C} 12 \mathrm{H} 18 \mathrm{~N} 2 \mathrm{O}$ & 207.14918 & & 6.57 & 1 \\
\hline 100 & $\mathrm{P}$ & Difenoxuron & $\mathrm{C} 16 \mathrm{H} 18 \mathrm{~N} 2 \mathrm{O} 3$ & 287.13898 & & 6.59 & 1 \\
\hline 101 & $\mathrm{P}$ & Spiroxamine & C18H35NO2 & 298.27408 & & 6.69 & 1 \\
\hline 102 & VD & Isoxicam & C14H13N3O5S & 336.06487 & & 6.69 & 5 \\
\hline 103 & VD & Valnemulin & C31H52N2O5S & 565.36698 & & 6.7 & 5 \\
\hline 104 & VD & Albendazole & $\mathrm{C} 12 \mathrm{H} 15 \mathrm{~N} 3 \mathrm{O} 2 \mathrm{~S}$ & 266.09578 & & 6.72 & 5 \\
\hline 105 & $P$ & Diuron & $\mathrm{C} 9 \mathrm{H} 10 \mathrm{Cl} 2 \mathrm{~N} 2 \mathrm{O}$ & 233.02428 & & 6.72 & 1 \\
\hline 106 & VD & Fenbufen & $\mathrm{C} 16 \mathrm{H} 14 \mathrm{O} 3$ & 255.10158 & & 6.76 & 5 \\
\hline 107 & VD & Meloxicam & $\mathrm{C} 14 \mathrm{H} 13 \mathrm{~N} 3 \mathrm{O} 4 \mathrm{~S} 2$ & 352.04202 & & 6.88 & 1.5 \\
\hline 108 & VD & Sulindac & C20H17FO3S & 357.09552 & & 6.89 & 5 \\
\hline 109 & MT & T2 Toxin & C24H34O9 & 484.25411 & $* * *$ & 6.91 & 1 \\
\hline 110 & $P$ & Azoxystrobine & $\mathrm{C} 22 \mathrm{H} 17 \mathrm{~N} 3 \mathrm{O} 5$ & 404.12408 & & 7.01 & 1 \\
\hline 111 & VD & Robenidine & $\mathrm{C} 15 \mathrm{H} 13 \mathrm{Cl} 2 \mathrm{~N} 5$ & 334.06208 & & 7.04 & 1 \\
\hline 112 & $P$ & Clomazon & $\mathrm{C} 12 \mathrm{H} 14 \mathrm{CINO} 2$ & 240.07858 & $* * * *$ & 7.11 & 1 \\
\hline 87 & $\mathrm{P}$ & Imazalil & $\mathrm{C} 14 \mathrm{H} 14 \mathrm{Cl} 2 \mathrm{~N} 2 \mathrm{O}$ & 297.05558 & & 7.26 & 1 \\
\hline 113 & $\mathrm{P}$ & Dimethomorph I & $\mathrm{C} 21 \mathrm{H} 22 \mathrm{CINO} 4$ & 388.13098 & & 7.27 & 1 \\
\hline 123 & VD & Flunixin & $\mathrm{C} 14 \mathrm{H} 11 \mathrm{~F} 3 \mathrm{~N} 2 \mathrm{O} 2$ & 297.08458 & & 7.32 & 5 \\
\hline 114 & $\mathrm{P}$ & Methiocarb & $\mathrm{C} 11 \mathrm{H} 15 \mathrm{NO} 2 \mathrm{~S}$ & 226.08968 & & 7.34 & 1 \\
\hline 115 & $\mathrm{P}$ & Isoxaben & $\mathrm{C} 18 \mathrm{H} 24 \mathrm{~N} 2 \mathrm{O} 4$ & 333.18088 & & 7.36 & 1 \\
\hline 116 & $P$ & Paclobutrazole & $\mathrm{C} 15 \mathrm{H} 20 \mathrm{CIN} 3 \mathrm{O}$ & 294.13678 & & 7.43 & 1 \\
\hline 117 & $P$ & Dimethomorph II & $\mathrm{C} 21 \mathrm{H} 22 \mathrm{CINO} 4$ & 388.13098 & & 7.5 & 1 \\
\hline 118 & VD & Fenbendazole & $\mathrm{C} 15 \mathrm{H} 13 \mathrm{~N} 3 \mathrm{O} 2 \mathrm{~S}$ & 300.08008 & $* * * *$ & 7.66 & 1 \\
\hline 119 & $P$ & Fenhexamid & $\mathrm{C} 14 \mathrm{H} 17 \mathrm{Cl} 2 \mathrm{NO} 2$ & 302.07088 & & 7.79 & 1 \\
\hline 120 & $P$ & Iprovalicarb & $\mathrm{C} 18 \mathrm{H} 28 \mathrm{~N} 2 \mathrm{O} 3$ & 321.21728 & & 7.82 & 1 \\
\hline 121 & VD & Phenylbutazone & $\mathrm{C} 19 \mathrm{H} 2 \mathrm{~N} 2 \mathrm{O} 2$ & 309.15978 & & 7.82 & 2.5 \\
\hline 122 & $\mathrm{P}$ & Flufenacet & $\mathrm{C} 14 \mathrm{H} 13 \mathrm{~F} 4 \mathrm{~N} 3 \mathrm{O} 2 \mathrm{~S}$ & 364.07378 & & 7.92 & 1 \\
\hline 124 & $P$ & Dodine & $\mathrm{C} 13 \mathrm{H} 29 \mathrm{~N} 3$ & 228.24338 & & 8.31 & 1 \\
\hline 125 & $P$ & Fenoxycarb & C17H19NO4 & 302.13868 & & 8.34 & 1 \\
\hline 126 & MT & Sterigmatocystin & $\mathrm{C} 18 \mathrm{H} 12 \mathrm{O} 6$ & 325.0707 & & 8.34 & $\begin{array}{c}1 \\
\text { Con }\end{array}$ \\
\hline
\end{tabular}


Table 1. Continued

\begin{tabular}{|c|c|c|c|c|c|c|c|}
\hline Index & Type & Compound name & Elemental composition & Exact mass* & & $\mathrm{RT}(\min )$ & Stock $(\mu \mathrm{g} / \mathrm{mL})$ \\
\hline 127 & $P$ & Spinosyn A & C41H65NO10 & 732.46808 & & 8.38 & 1 \\
\hline 128 & VD & Indomethacin & $\mathrm{C} 19 \mathrm{H} 16 \mathrm{CINO} 4$ & 358.08406 & & 8.38 & 5 \\
\hline 129 & VD & Diclofenac & $\mathrm{C} 14 \mathrm{H} 11 \mathrm{Cl} 2 \mathrm{NO} 2$ & 296.02398 & & 8.38 & 5 \\
\hline 130 & $P$ & Neburon & $\mathrm{C} 12 \mathrm{H} 16 \mathrm{Cl} 2 \mathrm{~N} 2 \mathrm{O}$ & 275.07128 & & 8.41 & 1 \\
\hline 131 & VD & Niflumic acid & $\mathrm{C} 13 \mathrm{H} 9 \mathrm{~F} 3 \mathrm{~N} 2 \mathrm{O} 2$ & 283.0689 & & 8.57 & 5 \\
\hline 132 & $P$ & Tebuconazole & $\mathrm{C} 16 \mathrm{H} 22 \mathrm{CIN} 3 \mathrm{O}$ & 308.15238 & & 8.57 & 1 \\
\hline 133 & $P$ & Penconazole & $\mathrm{C} 13 \mathrm{H} 15 \mathrm{Cl} 2 \mathrm{~N} 3$ & 284.07158 & & 8.7 & 1 \\
\hline 134 & $P$ & Mefenpyr-diethyl & $\mathrm{C} 16 \mathrm{H} 18 \mathrm{Cl} 2 \mathrm{~N} 2 \mathrm{O} 4$ & 373.07168 & & 8.82 & 1 \\
\hline 135 & $P$ & Propiconazole & $\mathrm{C} 15 \mathrm{H} 17 \mathrm{Cl} 2 \mathrm{~N} 3 \mathrm{O} 2$ & 342.07708 & & 8.85 & 1 \\
\hline 136 & $P$ & Hexaconazole & $\mathrm{C} 14 \mathrm{H} 17 \mathrm{Cl} 2 \mathrm{~N} 3 \mathrm{O}$ & 314.08218 & & 8.86 & 1 \\
\hline 137 & $P$ & Prochloraz & $\mathrm{C} 15 \mathrm{H} 16 \mathrm{Cl} 3 \mathrm{~N} 3 \mathrm{O} 2$ & 376.03808 & & 8.89 & 1 \\
\hline 138 & $P$ & Diazinon & $\mathrm{C} 12 \mathrm{H} 21 \mathrm{~N} 2 \mathrm{O} 3 \mathrm{PS}$ & 305.10838 & & 8.9 & 1 \\
\hline 139 & $P$ & Fenchlorazole-ethyl & $\mathrm{C} 12 \mathrm{H} 8 \mathrm{Cl} 5 \mathrm{~N} 3 \mathrm{O} 2$ & 401.91318 & & 8.93 & 1 \\
\hline 140 & $P$ & Phosalone & $\mathrm{C} 12 \mathrm{H} 15 \mathrm{CINO} 4 \mathrm{PS} 2$ & 367.99418 & & 8.95 & 1 \\
\hline 141 & $P$ & Pirimiphos-methyl & $\mathrm{C} 11 \mathrm{H} 20 \mathrm{~N} 303 \mathrm{PS}$ & 306.10358 & & 9.01 & 1 \\
\hline 142 & $P$ & Benzoximate & C18H18CINO5 & 364.09468 & & 9.05 & 1 \\
\hline 143 & $P$ & Pyrazophos & C14H20N3O5PS & 374.09338 & $* * * *$ & 9.15 & 1 \\
\hline 144 & $P$ & Difenconazole & $\mathrm{C} 19 \mathrm{H} 17 \mathrm{Cl} 2 \mathrm{~N} 3 \mathrm{O} 3$ & 406.07198 & & 9.33 & 1 \\
\hline 145 & VD & Mefenamic acid & $\mathrm{C} 15 \mathrm{H} 15 \mathrm{NO} 2$ & 242.11758 & & 9.4 & 5 \\
\hline 146 & $P$ & Fenoxaprop-p-ethyl & $\mathrm{C} 18 \mathrm{H} 16 \mathrm{CINO5}$ & 362.07898 & & 9.64 & 1 \\
\hline 147 & $P$ & Furathiocarb & $\mathrm{C} 18 \mathrm{H} 26 \mathrm{~N} 2 \mathrm{O} 5 \mathrm{~S}$ & 383.16348 & & 9.75 & 1 \\
\hline 148 & $P$ & Pirimiphos-ethyl & C13H24N3O3PS & 334.13488 & & 9.92 & 1 \\
\hline 149 & $P$ & Tralkoxydim & $\mathrm{C} 2 \mathrm{OH} 27 \mathrm{NO} 3$ & 330.20638 & & 10.4 & 1 \\
\hline 150 & $P$ & Pyridaben & $\mathrm{C} 19 \mathrm{H} 25 \mathrm{CIN} 2 \mathrm{OS}$ & 365.14488 & $* * * *$ & 11.09 & 1 \\
\hline 151 & VD & Lasalocid & С34H54O8 & 591.38918 & & 11.4 & 2 \\
\hline
\end{tabular}

$\mathrm{P}=$ pesticide; $\mathrm{VD}=$ veterinary drug; $\mathrm{MT}=$ mycotoxins; $\mathrm{PT}=$ plant toxin; $(\mathrm{m})=$ metabolite.

$*[\mathrm{M}+\mathrm{H}]^{+}$.

$* *[\mathrm{M}+2 \mathrm{H}]^{2+}$

$* * *\left[\mathrm{M}+\mathrm{NH}_{4}\right]^{+}$.

****Quantitative evaluation.

cient extraction of multiple classes of food/feed toxicants from various matrices [6].

To $2.5 \mathrm{~g}$ of sample, $5 \mathrm{~mL}$ of water was added and mixed using a vortex. In case of the dry feed matrix, the mixture was allowed to soak for $15 \mathrm{~min}$. Then $15 \mathrm{~mL}$ of acetonitrile containing $1 \%$ of formic acid was added and the sample was extracted by end-over-end shaking for $1 \mathrm{~h}$. The tube was centrifuged (10 $\mathrm{min}$ at $2000 \mathrm{rcf}$ ) and the clear extract was used for fortification. The final concentration of matrix equivalent in the extract was $0.125 \mathrm{~g} / \mathrm{mL}$.

To the extracts, aliquots of the stock-mix solutions, or intermediate solutions thereof, were added such that the matrix was not diluted by more than $10 \%$. The concentrations of the spiked extracts ranged from 1.25 to $31.25 \mathrm{ng} / \mathrm{mL}$. Since the sample is diluted eight times during the sample preparation, this corresponds to a concentration range from 10 to $250 \mathrm{ng} / \mathrm{g}$ in honey or feed samples. This was the concentration range for all pesticides and natural toxins. For veterinary drugs, the concentrations in the stock solutions varied (see Table 1) and, consequently, were correspondingly higher or lower. For sake of readability, this detail is not specified in each of the figures and tables in the Results and Discussion section, i.e., when reference is made to a level of $10 \mathrm{ng} / \mathrm{g}$, the actual levels for veterinary drugs are different for each compound and vary from $1 \mathrm{ng} / \mathrm{g}$ to $50 \mathrm{ng} / \mathrm{g}$.

\section{LC-Orbitrap Analysis}

The separation of the analytes were carried out using an (U-)HPLC system (Thermo Scientific Accela; Thermo Fisher Scientific, San Jose, CA, USA) equipped with a reversed-phase $C_{18}$ analytical column of $100 \mathrm{~mm} \times 2.0$ $\mathrm{mm}$ and $4 \mu \mathrm{m}$ particle size (Synergi $4 \mu \mathrm{m}$ Hydro-RP 80 $\AA$ A Phenomenex, Torrance, CA, USA). The column temperature was maintained at $35^{\circ} \mathrm{C}$. The injected sample volume was $5 \mu \mathrm{L}$.

Mobile phases A and B were water $/ 5 \%$ methanol and methanol $/ 5 \%$ water, respectively, both containing $2 \mathrm{mM}$ ammonium formate and $20 \mu \mathrm{L}$ formic acid/L. The chromatographic method held the initial mobile phase composition (100\% A) constant for $1 \mathrm{~min}$, followed by a linear gradient to $55 \% \mathrm{~B}$ after $3 \mathrm{~min}$, and a linear gradient to $100 \% \mathrm{~B}$ after $9 \mathrm{~min}$. This final condition was held for $11 \mathrm{~min}$ to ensure complete elution of matrix from the column. The flow rate used was 300 $\mu \mathrm{L} / \mathrm{min}$.

The HPLC system was connected to a single stage Orbitrap mass spectrometer (Exactive), through a heated electrospray interface (HESI-II; Thermo Fisher Scientific, San Jose, CA, USA), operating in positive ionization mode using the following operation parameters: electrospray voltage: $2.8 \mathrm{kV}$; sheath gas: 19 arbitrary units; auxiliary gas: 7 arbitrary units; all other source parameters were automatically tuned for maximum 
total ion current in the mass range between $m / z=150$ to $\mathrm{m} / \mathrm{z}=1000$ and minimum in-source fragmentation. The automatic gain control (AGC) was set at a target value of three million. Internal calibration was performed by single point calibration using the background ion of $n$-butyl benzene sulfonamide (n-BBS) at $m / z=$ 214.08963 in positive mode and $m / z=212.07507$ in negative mode.

Data processing was done by ToxID software (version 2.1.1, Thermo Fisher Scientific, San Jose, CA, USA) and manual validation.

\section{Mass Spectrometer}

Samples were introduced into the atmospheric pressure ionization (API) source by a liquid chromatographic system. Ions are transferred from the ion source through four stages of differential pumping using rfonly multipoles into a curved rf-only trapping quadrupole (C-trap). In the C-trap ions are accumulated and their energy dampened using a bath gas (nitrogen). Ions are then injected through three further stages of differential pumping using a curved lens system into the Orbitrap analyzer, where mass spectra are acquired via image current detection. The vacuum inside the Orbitrap mass analyzer is maintained below 1E-09 mbar. A schematic is available in the Supplemental Figure 2.

Automatic control of the number of ions in the Orbitrap is performed by measuring the total ion charge using a short prescan before the analytical scan and by calculating the ion injection time for the analytical scan from this value. For high scan rates, the previous analytical scan is used as a prescan to optimize the scan cycle time without compromising automatic gain control. Ion gating is performed using a fast split lens setup that ensures the precise determination of the ion injection time.

\section{Evaluation Set-Up}

A set of 151 pesticides, veterinary drugs, mycotoxins and plant toxins (see Table 1) was chosen for this evaluation. Based on injection of solvent standards, all of these analytes gave a good chromatographic peak shape and response. From this it would be expected that the theoretical detection limit of the analytes in samples should be of the order of $10 \mathrm{ng} / \mathrm{g}$ or lower, taking into account the eight $\times$ dilution factor from the sample preparation.

An LC-MS sequence was set up for injection of spiked extracts of honey and horse feed (levels corresponding to $0-10-25-50-100-250 \mathrm{ng} / \mathrm{g}$ in sample). Measurements were done at four resolving power settings (specified at $m / z 200$, FWHM) and scan speeds: 10,000 $(10 \mathrm{~Hz}), 25,000(4 \mathrm{~Hz}), 50,000(2 \mathrm{~Hz})$, and 100,000 (1 Hz). It shall be noted that resolving power of an Orbitrap mass spectrometer is inversely proportional to the square root of $m / z$, meaning that a resolving power of $10,000(100,000)$ defined at $m / z 200$ results in an effective resolving power of $8164(81,640)$ at $m / z 300$. For better readability, all resolving power settings mentioned in this article are defined at $m / z 200$, if not specified differently. Under the chromatographic conditions applied, at least eight data points across the peak were obtained at the lowest scan speed (for illustration of the effect of resolving power/scan speed on data points across the peak, see Supplemental Figure 3). For evaluation of mass accuracy, the mass at the apex of the chromatographic peak obtained in the extracted ion chromatogram was used.

For evaluation of quantitative performance, a set of spiked extracts was measured in triplicate with a resolving power of 100,000. Extracted ion chromatograms were created for a subset of compounds (indicated in Table 1) using a mass extraction window of \pm 5 ppm.

\section{Results and Discussion}

\section{General Considerations Regarding Residue/Contaminant Screening with Full Scan Mass Spectrometry}

In full scan mass spectrometry measurements, selectivity is obtained by creation of extracted ion chromatograms (XICs) of quasimolecular ions of the compound of interest. For trace level analysis in LC-MS, highresolution/accurate mass is generally used. This enables data analysis using the XICs of the exact mass of a quasimolecular ion with a narrow mass-extraction window, which provides the required selectivity. As will be shown in the next paragraph, the width of the mass-extraction window substantially affects the selectivity (i.e., number of interfering peaks in a certain chromatographic time domain, signal-to-noise ratio). The more narrow the setting of the mass-extraction window, the higher the selectivity. Correct mass assignment over the entire chromatographic elution profile of the analyte is important because it directly affects the width of the useable mass-extraction window in the data evaluation. In addition, it is an important parameter for peak assignment and identification/confirmation.

In broad screening methods, the full scan raw data needs to be searched for high numbers of analytes. In practice, it is not possible to do this manually, and automated library-based screening is necessary. Ideally, a list of tentatively detected targets should be automatically generated after analysis. For each analyte on the list, further examination of the available data, or even additional analysis, is required for full confirmation of compound identity. Since this takes additional time, it is desirable to minimize the number of detected components which are subsequently rejected. The number of these so-called false positives can be minimized using narrow mass-extraction windows and a low tolerance for mass accuracy. However, too strict criteria may result in analytes going undetected (false negatives) if mass assignment obtained during the measurement 
turns out to be insufficient or unreliable. For this reason, a thorough evaluation of mass assignment errors in complex samples and understanding of the parameters causing them is essential for automated broad screening methods.

\section{Mass Extraction Window and Selectivity}

After full scan LC-MS analysis, exact masses of quasimolecular ions, within a specific mass window will be extracted to search the data for the presence of residues or contaminants. In principle, the selectivity obtained during data evaluation increases with narrowing of the mass-extraction window. This is illustrated in Figure 1 for the pesticide pirimicarb $\left(\mathrm{C}_{11} \mathrm{H}_{18} \mathrm{~N}_{4} \mathrm{O}_{2}\right)$ in an animal feed matrix at the $10 \mathrm{ng} / \mathrm{g}$ level. Starting with an extraction window of $\pm 50 \mathrm{ppm}( \pm 12 \mathrm{mDa})$, a rather unspecific chromatogram is obtained. Taking a closer look at the expected retention time of pirimicarb (see inserts in Figure 1), clearly the analyte peak is obscured by interferences. By narrowing the mass-extraction window, the pirimicarb peak rises from the background and the signal-to-noise ratio $(\mathrm{S} / \mathrm{N})$ steadily improves. At \pm 2 ppm, the analyte peak is fully resolved. For the very complex sample injected into the system, only three distinct peaks are seen in the entire chromato-
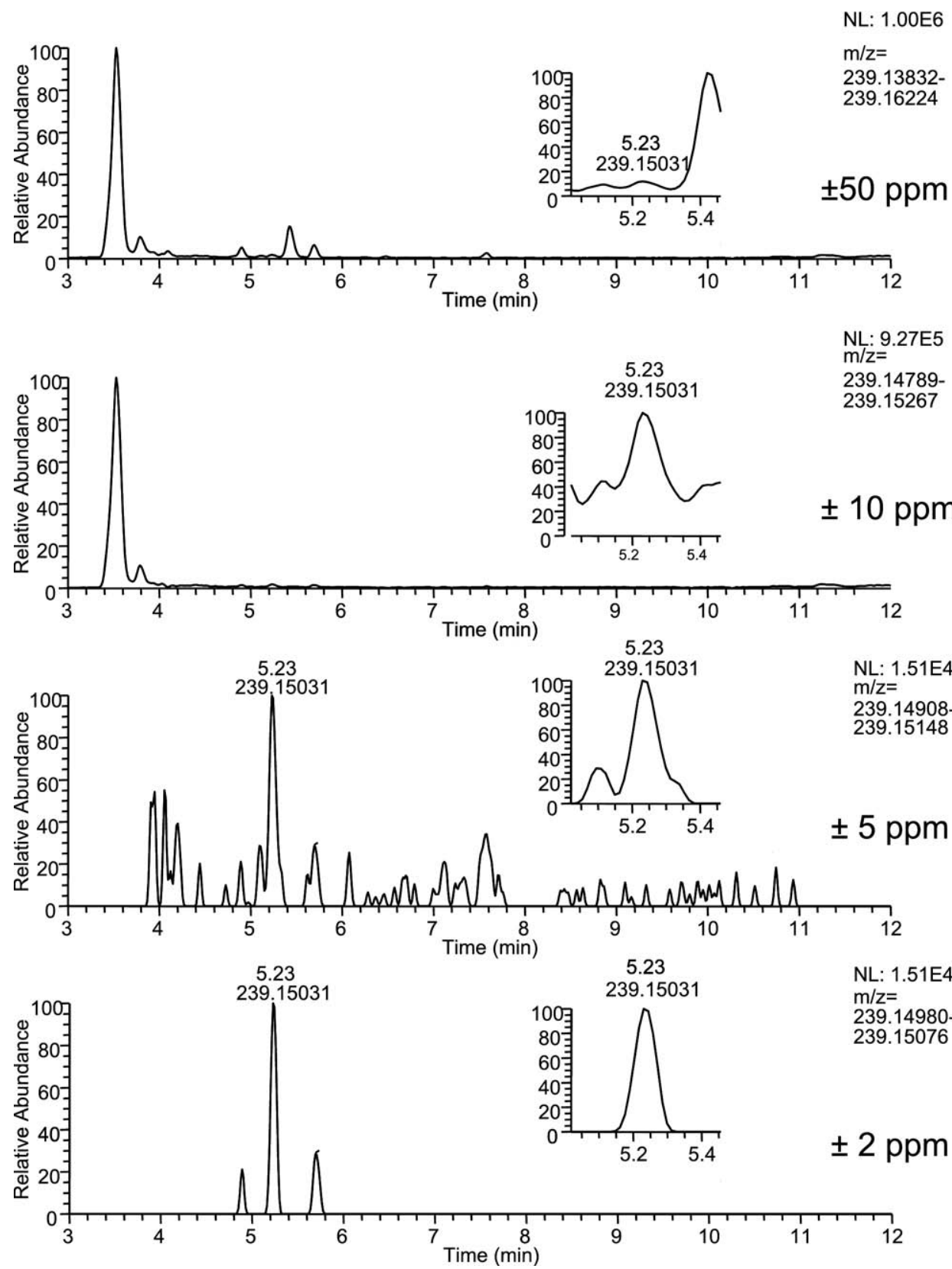

Figure 1. Effect of mass extraction window on selectivity. Extracted ion chromatograms for the pesticide pirimicarb $\left(\mathrm{MH}+, \mathrm{C}_{11} \mathrm{H}_{19} \mathrm{~N}_{4} \mathrm{O}_{2}, \mathrm{~m} / \mathrm{z}_{\text {theo. }}=239.15028\right.$, retention time $\left.=5.23 \mathrm{~min}\right)$ in animal feed matrix at $10 \mathrm{ng} / \mathrm{g}$; resolving power: 100,000. 
gram, clearly showing the very high selectivity that can be achieved. Conversely, it also shows that MS detection alone, even at this resolving power, does not result in unique analyte-specific detection, and that separation before MS detection is still required.

\section{Resolving Power and Mass Assignment for Analytes in Real Samples}

The use of narrow mass-extraction windows is only feasible when the mass spectrometer provides sufficient mass accuracy. Very good mass accuracy $(<5 \mathrm{ppm})$ has been reported for different types of mass analyzers, including TOF [21] and Orbitrap [16, 17]. These specifications are usually established for mass measurement of single isolated compounds. In the practice of multiresidue analysis, even with preseparation using HPLC or U-HPLC, analytes may co-elute with compounds from the matrix, or even with each other. In case of injection of complex mixtures, it is not unlikely that the exact mass of a co-eluting compound is close to that of an analyte. When the two mass profiles overlap (i.e., the two masses are not fully resolved), the measured mass profile is the sum of the two individual profiles. Depending on the difference between the two exact masses, their relative abundance, and the width of the individual mass profiles (which is determined by the resolving power of the MS), the top of the measured mass profile lies somewhere in between the two exact masses resulting in incorrect assignment of the mass of the target analyte. Consequently, for a given extract analyzed, the resolving power is a key parameter affecting the correct assignment of masses for analytes in residue analysis.

This is illustrated below by two examples in which samples have been measured with a resolving power of 10,000 and 100,000. The first example shows the coelution of two analytes Imazalil and Flunixin, which differ by $30 \mathrm{mDa}$ in their exact masses (Figure 2). The mass spectra at three time points across the Imazalil elution profile shows a mass accuracy better than $2 \mathrm{ppm}$ for all measurements of the high resolving experiment, but mass deviations up to 95 ppm were encountered for the measurement at a resolving power set at 10,000. This is due to Flunixin, which is partially coeluting with Imazalil (dashed line), and could not be resolved at the lower resolving power setting $(R=10,000)$. Both analytes form a broad peak (A simulation for the theoretical resolving power at $m / z 300(\mathrm{R}=8200)$ can be found in Supplemental Figure 4). The centroiding algorithm assigns a mass of 297.07214, which is 55.7 ppm apart of the theoretical $\mathrm{MH}^{+}$value of Imazalil (for Flunixin the mass assignment error in this case is $43.4 \mathrm{ppm}$ ). A resolving power setting of 100,000 provides more than
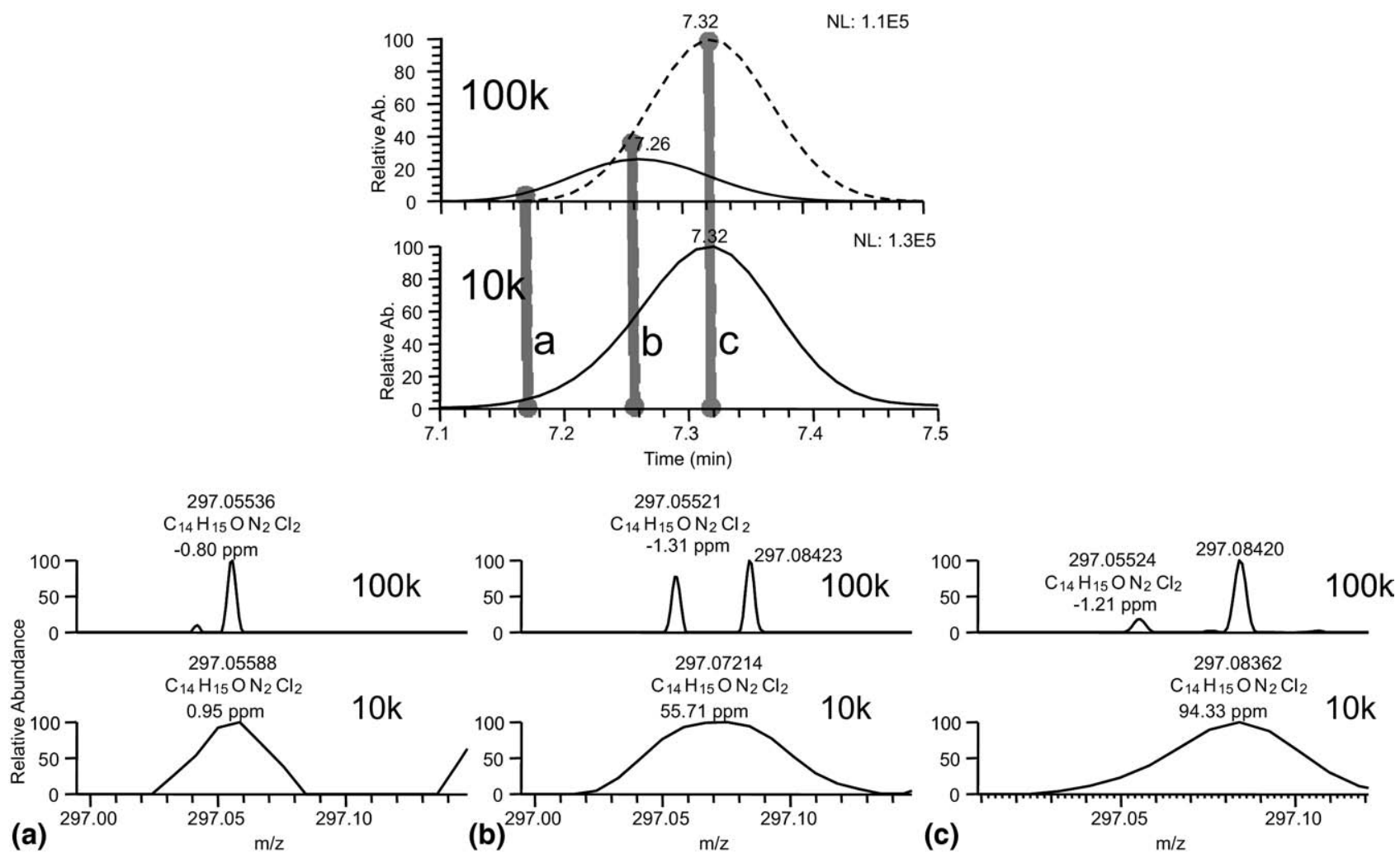

Figure 2. Effect of resolving power on assigned mass accuracy of two co-eluting analytes. Imazalil $\left(\mathrm{MH}+=297.05560, \mathrm{C}_{14} \mathrm{H}_{14} \mathrm{Cl}_{2} \mathrm{~N}_{2} \mathrm{O}, \mathrm{RT}=7.26 \mathrm{~min}\right)$ and Flunixin $\left(\mathrm{MH}+=297.08454, \mathrm{C}_{14} \mathrm{H}_{11} \mathrm{~F}_{3} \mathrm{~N}_{2} \mathrm{O}_{2}\right.$, $\mathrm{RT}=7.32 \mathrm{~min}$. Upper figure: extracted ion chromatograms ( $\pm 5 \mathrm{ppm}$ and $\pm 100 \mathrm{ppm}$, respectively). Bottom figures: mass profiles at two resolving power settings 10,000 (10 k) and 100,000 (100 k). 
sufficient resolution to detect both analytes, independently of each other, and consequently the masses are assigned correctly for both.

In the second example, co-elution of an analyte with matrix compounds occurs, resulting in interference at the same nominal mass. This is a more severe issue, since in complex samples elution behavior of matrix compounds cannot be predicted and may also vary between samples and even batches of the same sample source. With increasing complexity of the matrix there is an increasing risk to suffer from these interferences This is exemplary depicted for Isopyrin $(\mathrm{m} / \mathrm{z}=$ 246.16009); $25 \mathrm{ng} / \mathrm{g}$ ) in animal feed (Figure 3). Measurements were performed at four resolving power settings. A good peak shape and mass assignment over the entire chromatographic peak was observed at 100,000 and 50,000 . With a resolving power of 25,000 the peak shape deteriorated, since several data points showed mass deviations that exceeded the mass tolerance window of the XIC ( $\pm 5 \mathrm{ppm})$. At a resolving power of 10,000 this resulted in a complete loss of analyte response. Examining the associated mass spectra at the apex of the chromatographic peak in the XIC for each resolving power shows an interference at $\mathrm{m} / \mathrm{z}=246.17001$ (i.e., $10 \mathrm{mDa}$ difference with the target analyte). This interference was resolved at the two higher resolving power settings, but only partially at $R=25,000$ and not at all at $\mathrm{R}=10,000$. From Figure 3 it can be seen that at a resolving power of 25,000 and below, the assignment of masses is not reliable. Lower analyte concentration and/or a higher interference concentration (which is more or less a random variable), would result in substantial mass deviation of Isopyrin already at a resolving power of 25,000 , which, in turn, would result in a false negative response during screening.
From the above examples it becomes clear, that precision of the mass measurement and, in addition, correct assignment of masses, independent of the matrix, is a prerequisite for using narrow mass extraction windows, which, in turn, are required for reliable qualitative and quantitative analysis of small molecules in complex samples. To achieve this, a certain minimum resolving power is needed, which depends on the complexity of the sample and the concentration levels of both analytes and interferences.

\section{Resolving Power Requirements in Residue/Contaminant Screening}

To evaluate the application of full scan mass spectrometry for generic chemical screening assays, more insight into the resolving power requirements for precise mass measurement is needed. As a first step to provide this insight, the accuracy of mass assignment of all 151 analytes from Table 1 was determined for five concentration levels $(1.25-31.25 \mathrm{ng} / \mathrm{mL}$ corresponding to $10-$ $250 \mathrm{ng} / \mathrm{g}$ in the sample), at various resolving power settings and for two types of samples. Honey was chosen as a representative matrix of intermediate complexity, horse feed was chosen as a realistic worst case sample of high complexity. Honey and a compound feed were also chosen because they are typical examples where various types of contaminants (i.e., pesticides, veterinary drugs, and natural toxins) are relevant, and where wide-scope screening assays are highly beneficial.

In Table 2, a compilation of errors in the assigned masses is made for the lowest and the highest resolving power settings (i.e., 10,000 and 100,000). Since in routine

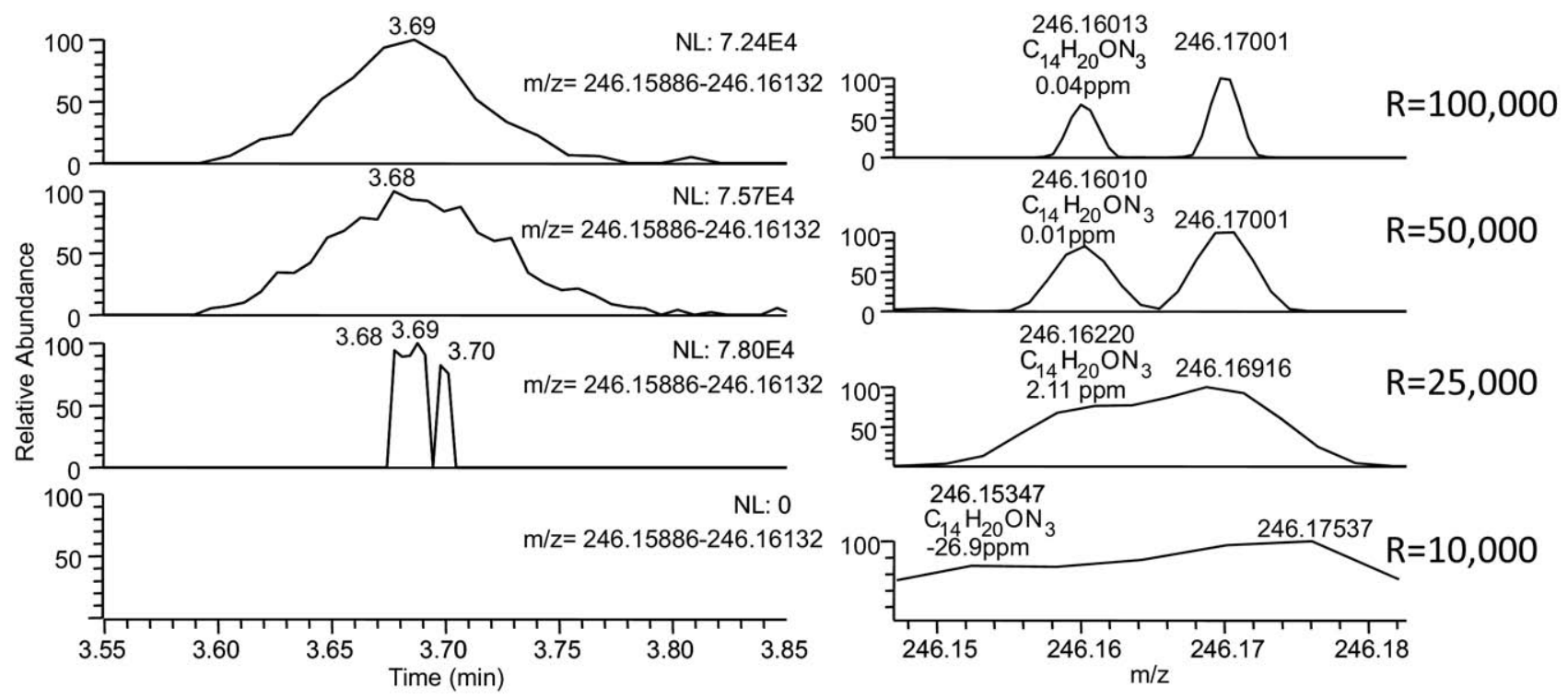

Figure 3. Effect of resolving power on assigned mass accuracy of an analyte in matrix. Isopyrin $\left(\mathrm{C}_{14} \mathrm{H}_{19} \mathrm{~N}_{3} \mathrm{O}, \mathrm{RT}=3.69 \mathrm{~min} ; \mathrm{MH}+=246.16009,25 \mathrm{ng} / \mathrm{g}\right.$ in animal feed. Left-hand side: XICs with \pm 5 ppm mass extraction window. Right-hand side: mass profiles of analyte and matrix interference at $\mathrm{RT}=3.69 \mathrm{~min}$. 
Table 2. Effect of resolving power, concentration and matrix on measured mass deviation of residues and contaminants

\begin{tabular}{|c|c|c|c|c|c|c|c|c|c|c|}
\hline \multirow{4}{*}{$\begin{array}{c}\text { Concentration } \\
\mathrm{ng} / \mathrm{g}\end{array}$} & \multicolumn{10}{|c|}{$\%$ of 151 analytes } \\
\hline & \multicolumn{5}{|c|}{ Resolution $=10,000$} & \multicolumn{5}{|c|}{ Resolution $=100,000$} \\
\hline & \multicolumn{5}{|c|}{ Mass deviation (ppm) } & \multicolumn{5}{|c|}{ Mass deviation (ppm) } \\
\hline & $<2$ & $2-5$ & $5-10$ & $10-25$ & $>25 / \mathrm{ND}$ & $<2$ & $2-5$ & $5-10$ & $10-25$ & $>25 / \mathrm{ND}$ \\
\hline \multicolumn{11}{|l|}{ Honey } \\
\hline 10 & 79 & 12 & 5 & 3 & 1 & 99 & 0 & 0 & 0 & 1 \\
\hline 25 & 83 & 12 & 5 & 0 & 0 & 100 & 0 & 0 & 0 & 0 \\
\hline 50 & 88 & 10 & 2 & 0 & 0 & 100 & 0 & 0 & 0 & 0 \\
\hline 100 & 94 & 4 & 2 & 0 & 0 & 100 & 0 & 0 & 0 & 0 \\
\hline 250 & 91 & 8 & 1 & 0 & 0 & 100 & 0 & 0 & 0 & 0 \\
\hline \multicolumn{11}{|l|}{ Animal feed } \\
\hline 10 & 11 & 17 & 13 & 24 & 35 & 93 & 1 & 0 & 0 & 6 \\
\hline 25 & 22 & 25 & 16 & 20 & 17 & 99 & 0 & 0 & 0 & 1 \\
\hline 50 & 32 & 34 & 20 & 0 & 14 & 99 & 0 & 0 & 0 & 1 \\
\hline 100 & 42 & 39 & 7 & 0 & 12 & 100 & 0 & 0 & 0 & 0 \\
\hline 250 & 45 & 41 & 10 & 0 & 4 & 100 & 0 & 0 & 0 & 0 \\
\hline
\end{tabular}

practice mass deviations exceeding 25 ppm are considered not useful (lower selectivity, lower S/N, increased rate of false positives), peaks with a mass deviation $>25$ ppm were excluded from the results and flagged as "not detected." It should be noted that nondetection can also be caused by reduced analyte response when coeluting with matrix due to (1) ion suppression in the ion-source and (2) exceeding the maximum dynamic range for the mass spectrometer.

For the analysis of honey samples, the measurements performed at $\mathrm{R}=100,000$ showed excellent mass accuracy $(<2$ ppm) down to the lowest concentration levels for all analytes. Only one analyte out of 151 could not be detected at the $10 \mathrm{ng} / \mathrm{g}$ level. The 10,000 resolving power experiment showed increasing mass errors with decreasing analyte concentrations. Even at the relatively high levels of 250 and $100 \mathrm{ng} / \mathrm{g}$, mass deviations outside the instrument specification of $<2 \mathrm{ppm}$ were observed for a number of analytes due to matrix interferences. These mass deviations increased to 10-25 ppm at the lowest concentration levels.

As expected, for the more complex animal feed extract, the effect of resolving power and analyte concentration on the correct assignment of masses was much more pronounced. While excellent mass accuracy was still obtained for virtually all analytes down to the $10 \mathrm{ng} / \mathrm{g}$ level at the highest resolving power, a resolving power of 10,000 was clearly insufficient to maintain accurate mass assignment for the target compounds. Even at the highest analyte concentrations, less than $50 \%$ of the analytes were detected with a mass accuracy better than $2 \mathrm{ppm}$. In this complex matrix, the number of correctly assigned masses decreased dramatically for lower analyte concentrations. At the $10 \mathrm{ng} / \mathrm{g}$ level, 35\% (44 out of 151) of the analytes could not be detected when using a mass extraction window of $\pm 25 \mathrm{ppm}$.

The effects of resolving power on mass assignment at settings between 10,000 and 100,000 was further studied for the analysis of honey and feed samples with an analyte concentration of $25 \mathrm{ng} / \mathrm{g}$ at a resolving power of 25,000 and 50,000. These results are summarized in Table 3. For honey, a resolving power of 25,000 was sufficient to obtain assignments with excellent mass accuracy for all analytes. Higher resolving power is not strictly necessary for good screening performance in this case. Using the intermediate resolving power $(\mathrm{R}=$ 25,000 ) enables faster scan rates ( $4 \mathrm{~Hz}$ and, therefore, better compatibility with narrow peaks such as obtained with U-HPLC). Alternatively, additional acquisition events can be done (switching between positive and negative ion mode, measurement with and without fragmentation), which are outside the scope of this paper. As can be seen from Table 3, higher minimum resolving power is required in case of highly complex matrices, such as animal feed. Aiming for a detection rate of $>95 \%$, a resolving power setting of 50,000 is

Table 3. Effect of resolving power on mass assignment of residues and contaminants* in a matrix of intermediate and high complexity

\begin{tabular}{lrrrrr}
\hline & \multicolumn{5}{c}{ \% of 151 analytes } \\
\cline { 2 - 6 } & \multicolumn{5}{c}{ Mass deviation (ppm) } \\
\cline { 2 - 6 } Resolution & $<2$ & $2-5$ & $5-10$ & $10-25$ & $>25 /$ ND \\
\hline \hline Honey & 83 & 12 & 5 & 0 & 0 \\
10,000 & 100 & 0 & 0 & 0 & 0 \\
25,000 & 100 & 0 & 0 & 0 & 0 \\
50,000 & 100 & 0 & 0 & 0 & 0 \\
100,000 & & & & & \\
Animal feed & 22 & 25 & 16 & 20 & 17 \\
10,000 & 41 & 17 & 26 & 2 & 14 \\
25,000 & 93 & 4 & 1 & 0 & 2 \\
50,000 & 99 & 0 & 0 & 0 & 1 \\
100,000 & &
\end{tabular}

${ }^{*}$ Concentration of analytes $25 \mathrm{ng} / \mathrm{g}$. 
required for a mass deviation criteria of $<5 \mathrm{ppm}$. With a more stringent mass accuracy requirement of $<2$ ppm, a resolving power setting of 100,000 is needed.

\section{Quantitative Aspects}

Following the qualitative screening the next step is quantification of the analytes found. Especially for frequently detected analytes, (multi-level) calibration standards may be analyzed together with the samples to allow calculation of the concentration, or to estimate the concentration relative to targeted legal limits.

It has already been shown (Figures 1 and 3), that the mass-extraction window (i.e., resolving power and mass assignment accuracy) has a significant impact on selectivity and peak shape and, therefore, also on quantification. This is illustrated in more detail in Figure 4. Mass measurement of isoproturon in horse feed at a resolving power of 10,000 (Figure $4 \mathrm{e}-\mathrm{h}$ ) resulted in a mass assignment errors for several scans across the chromatographic peak. Only a few data points across the chromatographic peak had mass deviations below \pm 2 ppm. Consequently, a "spike-like" peak is obtained with a 2 ppm mass-extraction window. This will cause inconsistencies for automated integration, and result in an underestimation of the analyte concentration. Expanding the mass extraction window to $5 \mathrm{ppm}$ results in quite a few more signals within this window, but the chromatographic peak shape is still not sufficient for quantitation. Further increasing the window size to 10 ppm results in a peak shape, which is cut at the edges. This situation does not improve up to a window size of $25 \mathrm{ppm}$. Re-analysis of the same sample at a resolving power of 100,000 (Figure $4 a-d)$, ensuring a correct mass assignment of $<2$ ppm for all data points across the peak, resulted in a good chromatographic peak shape and consistent analyte response. The behavior at 10,000 resolving power in this case is caused by an unresolved matrix interference (Figure 4 , i and k), which is $\sim 11$ $\mathrm{mDa}$ apart. Consequently for low analyte levels in complex samples, high resolving power $(50,000$ or higher) is necessary to avoid peak distortion when using narrow mass-extraction windows, needed for appropriate selectivity. Similar observations are also made because of analyte-analyte interferences. As an example, the XICs of Imalazil at different resolving power settings and different extraction window sizes are shown in the supplemental data (Supplemental Figure 5).

The linearity of the analyte response for a range of concentrations was studied for a subset of 14 analytes (indicated in Table 1), representing the different molecular weights and retention times, in the honey and feed matrix.

The same general trends were observed for all analytes investigated. In honey, the slope of the response curve was higher than in horse feed (Figure 5). This is due to ion suppression within the electrospray ion

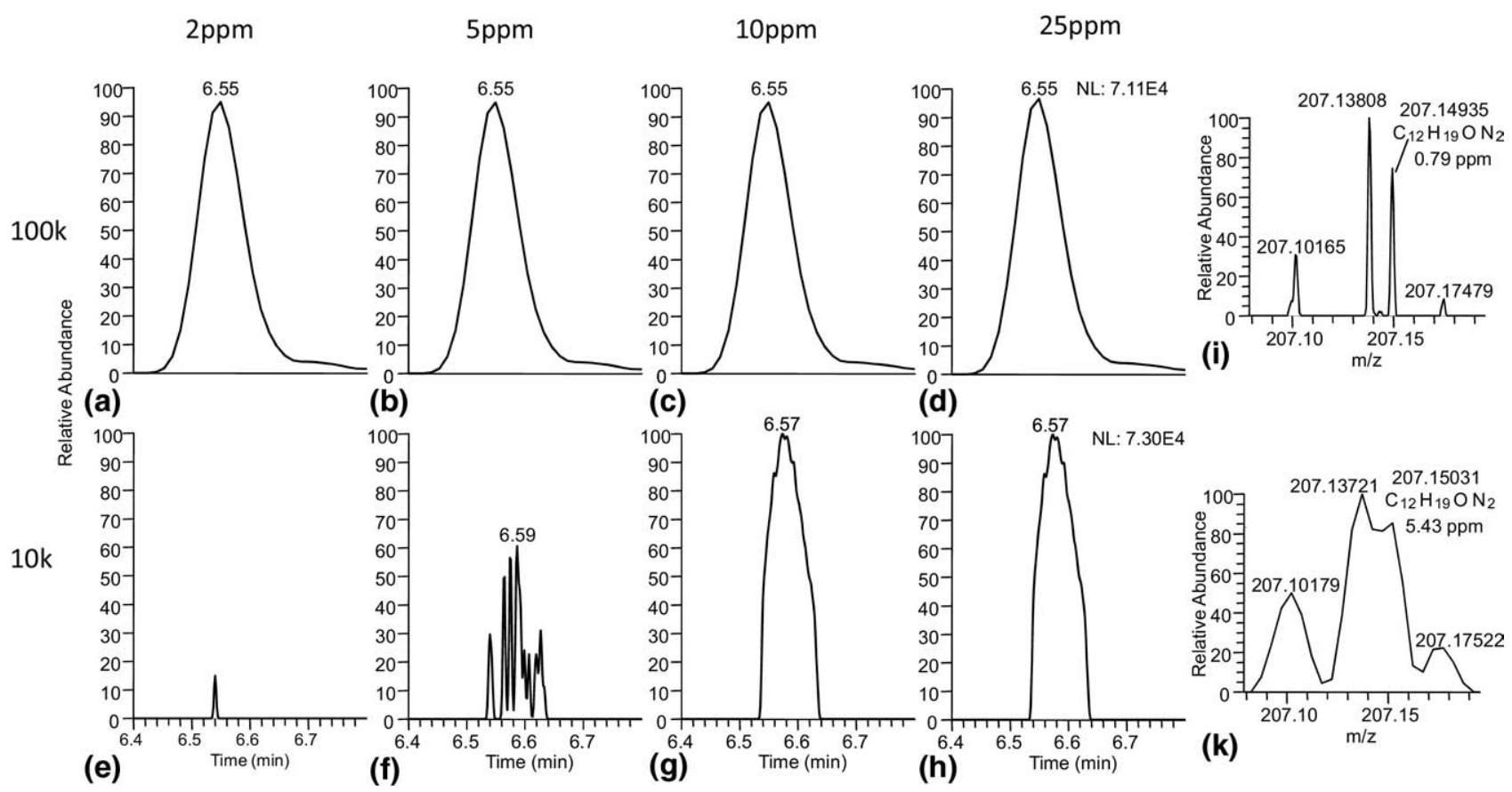

Figure 4. Extracted ion chromatograms with different mass extraction windows at high (100 k; a-d) and medium (10 k; e-h) resolving power of isoproturon $\left(\mathrm{C}_{12} \mathrm{H}_{18} \mathrm{~N}_{2} \mathrm{O}\right)$ at a concentration level of 25 $\mathrm{ng} / \mathrm{g}$ in horse feed matrix. Also shown is the molecular ion region at both resolving power settings, showing an resolved interference at $\mathrm{m} / \mathrm{z}=207.13808$ in the $\mathrm{R}=100,000$ spectrum (i) and the same interference-not resolved from the analyte-in the lower resolved mass spectrum (k). Absolute scale for all windows (7.11 E4 and 7.30 E4, respectively). 
source, a commonly observed phenomenon in LC-MS, which is usually more pronounced for samples with high amounts of co-extractants. The deviation between theoretical and calculated concentration, using the measured response and the equation of the calibration curve, was determined. Using a linear fit without weighing, this deviation was generally less than $20 \%$ except for the lowest concentration level (10 ng/g). At this level, a positive bias was observed for a number of analytes (typically 30\%-40\%, and higher in some cases). The accuracy in quantification could be improved using a weighing factor $(1 / x)$ or quadratic fitting. An example of the latter is shown in Figure 6. Using quadratic fitting, the deviations were mostly less than $10 \%$ for all concentration levels studied. The reason for the observed nonlinear behavior of some analytes could not be readily explained and is subject to further investigation.

\section{Conclusions}

Reliable qualitative screening and quantification in food/feed toxicant analysis with LC coupled to high mass accuracy MS detection is only possible when correct masses are assigned throughout the entire experiment. For this, the resolving power has to be fit-for-purpose. Since the resolving power needed is mainly determined by the ratio of the analyte concentration relative to co-eluting matrix interferences, the optimum setting depends on the type of sample, the analyte concentration, and the sample preparation before LC-MS analysis.

With straightforward generic extraction procedures, typically used in broad screening methods, a first evaluation shows that a resolving power of 7000-10,000 [ranges given here reflect the dependency of mass resolving power on $\mathrm{m} / \mathrm{z}$ with Orbitrap-MS, and correspond to actual resolving power at $m / z 400$ and $m / z 200$, respectively] can be sufficient for detection of analytes in samples of intermediate complexity, at levels down to $25 \mathrm{ng} / \mathrm{g}$, with mass errors below $5 \mathrm{ppm}$. For lower levels and/or more precise mass assignment, a higher resolving power $(18,000-25,000)$ is needed. In highly

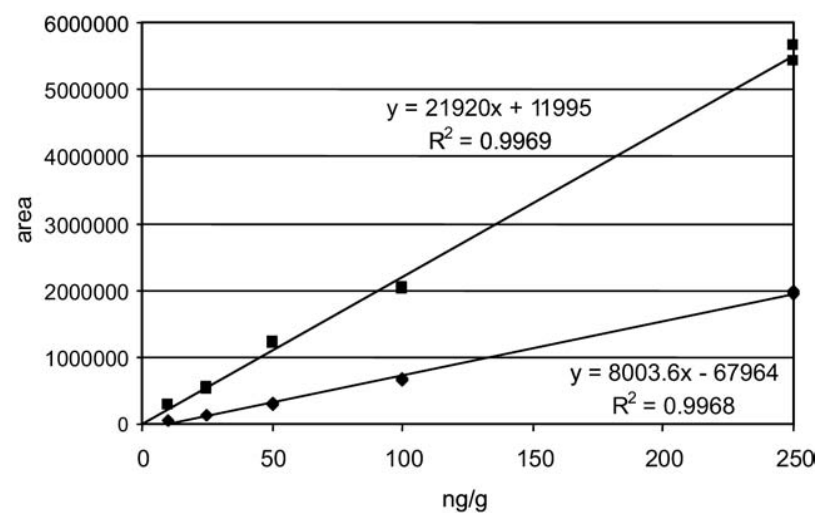

Figure 5. Calibration curves (linear without weighing) for carbendazim in honey (upper) and horse feed (lower).

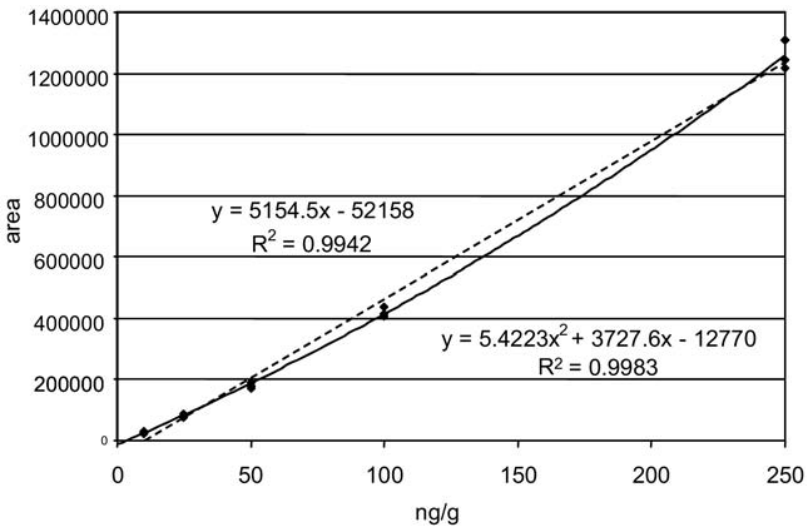

Figure 6. Calibration curves of dimethoate in horse feed extracts using linear and quadratic fitting.

complex extracts, a resolving power of $35,000-50,000$ or even $70,000-100,000$ is required. This observation is in agreement with results reported by others [13, 22]. A more comprehensive exploration involving a wider variety of matrices should give more insight in categorization of complexity of samples.

Knowing about the minimum required resolving power is useful for Orbitrap based experiments, since it is directly linked to the scan speed. Although, in principle, a maximum resolving power will provide the best qualitative and quantitative performance, the use of lower resolving power settings, where applicable, allows the use of faster scan rates (better compatibility with fast LC separation). From this work, it can also be concluded that single stage Orbitrap-MS is a very useful tool with high potential for efficient automated screening in the field of food and feed safety.

\section{Acknowledgments}

The authors thank Dr. Hans Pfaff for software support, Dr. Thomas Moehring and Dr. Robert Malek for discussions and reviewing, and Dr. Lester Taylor for kindly reviewing the manuscript.

\section{Appendix A Supplementary Data}

Supplementary material associated with this article may be found in the online version at doi:10.1016/ j.jasms.2009.05.010.

\section{References}

1. Regulation (EC) No 396/2005 of the European Parliament and of the Council on maximum residue levels of pesticides in or on food and feed of plant and animal origin and amending Council Directive 91/414/ EEC. Official Journal of the European Union. 2005, 16(3), L 70/1.

2. USDA, Foreign Agricultural Service, maximum residue limit database, http://www.fas.usda.gov/htp/MRL.asp January, 2009.

3. Directive 2002/32/EC of the European Parliament and of the Council on undesirable substances in animal feed. Official Journal of the European Communities 2002, 30(5), L 140/10.

4. Regulation (EC) No. 1881/2006 of 19 December 2006 setting maximum levels for certain contaminants in foodstuffs. Official Journal of the European Union 2006, 20(2), L 264/5.

5. Council Regulation (EEC) No. 2377/90 of 26 June 1990 laying down a Community procedure for the establishment of maximum residue 
limits of veterinary medicinal products in foodstuffs of animal origin. Official Journal of the European Communities. 1990, 18, L 224/1.

6. Mol, H. G.; Plaza-Bolanos, P.; Zomer, P.; de Rijk, T. C.; Stolker, A. A.; Mulder, P. P. Toward a generic extraction method for simultaneous determination of pesticides, mycotoxins, plant toxins, and veterinary drugs in feed and food matrixes. Anal. Chem. 2008, 80(24), 9450-9459.

7. Berger, U.; Haukas, M. Validation of a screening method based on liquid chromatography coupled to high-resolution mass spectrometry for analysis of perfluoroalkylated substances in biota. J. Chromatogr. A 2005, 1081(2), 210-217.

8. Ferrer, I.; Thurman, E. M. Multi-residue method for the analysis of 101 pesticides and their degradates in food and water samples by liquid chromatography/time-of-flight mass spectrometry. J. Chromatogr. A 2007, 1175(1), 24-37.

9. Garcia-Reyes, J. F.; Hernando, M. D.; Ferrer, C.; Molina-Diaz, A.; Fernandez-Alba, A. R. Large scale pesticide multiresidue methods in food combining liquid chromatography-time-of-flight mass spectrometry and tandem mass spectrometry. Anal. Chem. 2007, 79(19), 7308etry and

10. Thurman, E. M.; Ferrer, I.; Zweigenbaum, J. A. High resolution and accurate mass analysis of xenobiotics in food Anal. Chem. 2006, 78(10), 6703-6708.

11. Kaufmann, A.; Butcher, P.; Maden, K.; Widmer, M. Quantitative multiresidue method for about 100 veterinary drugs in different meat matrice by sub 2-microm particulate high-performance liquid chromatography coupled to time of flight mass spectrometry. J. Chromatogr. A 2008, 1194(1), 66-79.

12. Stolker, A. A.; Rutgers, P.; Oosterink, E.; Lasaroms, J. J.; Peters, R. J.; van Rhijn, J. A.; Nielen, M. W. Comprehensive screening and quantification of veterinary drugs in milk using UPLC-ToF-MS. Anal. Bioanal. Chem. 2008, 391(6), 2309-2322.

13. Nielen, M. W.; van Engelen, M. C.; Zuiderent, R.; Ramaker, R. Screening and confirmation criteria for hormone residue analysis using liquid chromatography accurate mass time-of-flight, Fourier transform ion cyclotron resonance and Orbitrap mass spectrometry techniques. Anal. Chim. Acta 2007, 586(1/2), 122-129.

14. Makarov, A. Electrostatic axially harmonic orbital trapping: A highperformance technique of mass analysis. Anal. Chem. 2000, 72(6), 11561162.

15. Makarov, A.; Denisov, E.; Kholomeev, A.; Balschun, W.; Lange, O.; Strupat, K.; Horning, S. Performance evaluation of a hybrid linear ion trap/Orbitrap mass spectrometer. Anal. Chem. 2006, 78(7), 2113-220.

16. Makarov, A.; Denisov, E.; Lange, O.; Horning, S. Dynamic range of mass accuracy in LTQ Orbitrap hybrid mass spectrometer. J. Am. Soc. Mass Spectrom. 2006, 17(7), 977-982.

17. Olsen, J. V.; de Godoy, L. M.; Li, G.; Macek, B.; Mortensen, P.; Pesch, R. Makarov, A.; Lange, O.; Horning, S.; Mann, M. Parts per million mass accuracy on an Orbitrap mass spectrometer via lock mass injection into a C-trap. Mol. Cell. Proteom. 2005, 4(12), 2010-2021.

18. Perry, R. H.; Cooks, R. G.; Noll, R. J. Orbitrap mass spectrometry: Instrumentation, ion motion, and applications. Mass Spectrom. Rev. 2008, 27(6), 661-699.

19. Scigelova, M.; Makarov, A. Orbitrap mass analyzer-overview and applications in proteomics. Proteomics 2006, 6 Suppl 2, 16-21.

20. Breitling, R.; Pitt, A. R.; Barrett, M. P. Precision mapping of the metabolome. Trends Biotechnol. 2006, 24(12), 543-548.

21. Ferrer, I.; Thurman, E. M. Measuring the mass of an electron by LC/TOF-MS: A study of "twin ions". Anal. Chem. 2005, 77(10), 33943400 .

22. van der Heeft, E.; Bolck, Y. J. C.; Beumer, B.; Nijrolder, A. W. J. M.; Stolker, A. A. M.; Nielen, M. W. F. Full-scan accurate mass selectivity of ultra-performance liquid chromatography combined with time-of-flight and Orbitrap mass spectrometry in hormone and veterinary drug residue analysis. J. Am. Soc. Mass Spectrom. 2009, 20(3), 451-463. 